\title{
USO DE MODELOS NEURONAIS ASSOCIADOS A ALGORITMOS EVOLUTIVOS DE OTIMIZAÇÃO COMO SUPORTE À PREPARAÇÃO DE FLUIDOS DE PERFURAÇÃO
}

\author{
M. L. V. VARGAS ${ }^{1}$, A. G. P. MORAES ${ }^{1}$, L. A. CALÇADA ${ }^{2}$, C. M. SCHEID ${ }^{2}$ e \\ L. A. C. MELEIRO ${ }^{2}$ \\ ${ }^{1}$ Universidade Federal Rural do Rio de Janeiro, Discente do Curso de Engenharia Química \\ ${ }^{2}$ Universidade Federal Rural do Rio de Janeiro, Departamento de Engenharia Química \\ E-mail para contato: meleiro@ufrrj.br
}

\begin{abstract}
RESUMO - A viscosidade aparente dos fluidos de perfuração é uma das principais variáveis que devem ser controladas durante a operação, onde aditivos químicos são empregados para corrigir suas propriedades reológicas. No entanto, a medida desta variável é feita off-line e obtida com algum atraso. Este trabalho teve como objetivo desenvolver uma ferramenta computacional capaz de estimar a viscosidade aparente de um fluido de perfuração em tempo real, além de determinar as correções necessárias na sua composição, caso seja necessário. Esta ferramenta é baseada em um algoritmo de otimização evolutivo, os Algoritmos Genéticos (AG), associado a um modelo matemático do processo representado por uma rede neuronal artificial (RNA) do tipo feedforward com camadas múltiplas (Multilayer Perceptron - MLP). As entradas da RNA são os dados experimentais da composição e da temperatura do fluido e a saída da rede são os respectivos valores de viscosidade aparente. A partir do algoritmo de otimização AG/RNA proposto é possível determinar a composição adequada do fluido para atingir a viscosidade aparente desejada, seja na etapa inicial de preparo do fluido, seja durante o procedimento de correção de sua composição devido a eventuais perturbações que ocorrem durante a perfuração do poço. O desempenho do algoritmo foi avaliado através de experimentos em laboratório que demonstraram o grande potencial desta estratégia.
\end{abstract}

\section{INTRODUÇÃO}

Apesar de existir uma série de sensores capazes de controlar as propriedades dos fluidos de perfuração, que podem ser físicas ou químicas, nem todas as variáveis são efetivamente medidas como, por exemplo, a viscosidade aparente. A medida dessa variável ocorre através de ensaios em laboratórios pela coleta de pequenas amostras de fluidos nos tanques de armazenamento. Somente a partir dos valores obtidos, são empregados os aditivos necessários para corrigir as propriedades reológicas dos fluidos para valores exigidos naquela etapa de perfuração (TAVARES, 2006; THOMAS et al, 2001).

A escolha do tipo de fluido durante a perfuração depende das informações obtidas em campo, como o tipo de formação geológica que está sendo perfurada, a faixa de temperatura a 
que o fluido será submetido, a qualidade da água disponível e os aspectos ecológicos e ambientais envolvidos. A partir dessas considerações, os fluidos devem exercer funções semelhantes, porém, com desempenhos diferenciados (BOURGOYNE JR et al., 1986).

Os fluidos à base de água são os mais empregados nos processos de perfuração por possuírem um baixo custo comparado aos demais, serem biodegradáveis e se dispersarem facilmente na coluna d'água. Tais fluidos consistem numa mistura de sólidos, líquidos e aditivos químicos que são empregados a fim de melhorar seu desempenho. A proporção entre os componentes básicos e as interações entre eles provoca sensíveis modificações nas propriedades do fluido. Consequentemente, a composição é o principal fator a considerar no controle das suas propriedades (THOMAS et al., 2001).

Os sólidos utilizados no meio aquoso podem ser ativos ou inertes. Dentre os sólidos inertes o adensante mais utilizado é a barita ou baritina. Já os sólidos ativos são aditivos que atuam no controle da reologia, evitando a perda de fluido para as formações rochosas e melhorando o carregamento de cascalhos. Os sólidos ativos podem ser polímeros, surfactantes, sais ou bentonitas. Os polímeros mais utilizados na indústria petrolífera são a goma xantana e a CMC (carboximetilcelulose). As bentonitas são classificadas como argilas e podem associar-se de diferentes maneiras, influenciando diretamente na qualidade e na eficiência dos fluidos. A atuação dessas argilas no campo petrolífero se dá pela alta retenção de água, conferindo ao fluido boas propriedades viscosificantes, formadoras de gel e controladoras de filtração (GUIMARÃES, 2007; THOMAS et al., 2001).

O objetivo desse trabalho foi desenvolver um aplicativo baseado em métodos de otimização associados a modelos neuronais capazes de determinar em tempo real as correções na composição dos aditivos do fluido de perfuração durante a operação.

\section{MATERIAIS E MÉTODOS}

\subsection{Materiais}

Neste trabalho, utilizou-se um fluido a base de água, tendo em vista a facilidade de preparo assim como suas vantagens destacadas na seção anterior. Os aditivos utilizados no preparo dos fluidos foram barita, bentonita e CMC. A primeira tem função de adensante, enquanto as outras duas são viscosificantes. $\mathrm{O}$ fornecedor da barita, bentonita e CMC usadas na obtenção do conjunto de treinamento foi a empresa Brasilminas, situada em Guarulhos, SP.

A homogeneização dos fluidos foi realizada com o agitador Hamilton Beach $®$ com três velocidades (13000, 16000 e $18000 \mathrm{rpm})$. A temperatura do fluido foi controlada por um banho termostatizado Technal ${ }^{\circledR}$ Te-2005, acoplado a um copo encamisado capaz de circular a água na faixa de -10 a $80^{\circ} \mathrm{C}$. A viscosidade aparente dos fluidos foi obtida através do o viscosímetro FANN 35A a 300 rpm. Os equipamentos descritos são ilustrados na Figura 1. 
Figura 1 - Agitador Hamilton Beach ${ }^{\circledR}$, banho termostatizado e viscosímetro FANN 35A.
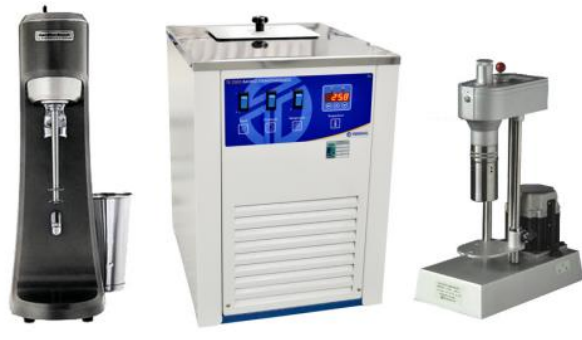

\subsection{Planejamento Experimental}

Neste trabalho, a fim de obter dados experimentais da viscosidade aparente dos fluidos, foi realizado um planejamento fatorial de três níveis com ponto central em triplicata e considerando quatro variáveis. As três primeiras variáveis consistem na concentração dos aditivos: CMC, bentonita e barita. Como na prática a temperatura do fluido de perfuração que retorna do poço é diferente da temperatura do ponto de injeção, esta variável também foi considerada para avaliar sua influência na viscosidade aparente. Estes fatores foram codificados em três níveis: baixo (-1), médio (0) e alto (1), conforme a Tabela 1.

Tabela 1 - Níveis utilizados no planejamento experimental.

\begin{tabular}{|c|c|c|c|}
\hline Componentes/Níveis & -1 & 0 & 1 \\
\hline \hline Temperatura $\left({ }^{\circ} \mathrm{C}\right)$ & 20 & 40 & 60 \\
\hline CMC $\left(\mathrm{g} / 300 \mathrm{~mL} \mathrm{H}_{2} \mathrm{O}\right)$ & 0,50 & 1,00 & 1,50 \\
\hline Bentonita $\left(\mathrm{g} / 300 \mathrm{~mL} \mathrm{H}_{2} \mathrm{O}\right)$ & 3,50 & 7,00 & 10,50 \\
\hline Barita $\left(\mathrm{g} / 300 \mathrm{~mL} \mathrm{H}_{2} \mathrm{O}\right)$ & 7 & 14 & 21 \\
\hline
\end{tabular}

\subsection{Procedimento Experimental}

Os aditivos foram pesados e adicionados aos poucos e sob constante agitação no agitador Hamilton Beach®, que continha previamente $300 \mathrm{~mL}$ de água. Durante o processo de mistura e adição dos componentes, a velocidade do agitador foi mantida entre 13000 e 16000 rpm. Após esse processo, a velocidade foi levada a $18000 \mathrm{rpm}$ por 10 minutos para garantir a homogeneização dos fluidos. Completa a agitação, os fluidos permaneceram em repouso por 24 horas para que os polímeros atingissem total hidratação, seguindo a norma N-2605 (PETROBRAS, 1998).

Após o intervalo de repouso os fluidos foram colocados no copo encamisado e levados ao viscosímetro FANN 35A para determinar sua viscosidade aparente. A temperatura foi controlada através do banho térmico acoplado ao copo encamisado e um termômetro foi colocado dentro do fluido para verificar o equilíbrio térmico. As medições da viscosidade aparente foram obtidas a $300 \mathrm{rpm}$ e o viscosímetro permaneceu nesta rotação durante todo o experimento para manter o fluido homogêneo e assegurar a ausência de um gradiente de temperatura no interior do recipiente. 
Como os modelos baseados em RNA geralmente exigem grande quantidade de dados para fornecer resultados confiáveis, foi realizado um procedimento complementar para aumentar o conjunto de dados originais. Este procedimento consiste na medição da viscosidade aparente em temperaturas intermediárias aos níveis especificados. Através deste procedimento, foi possível obter 384 dados experimentais relacionando as concentrações de aditivos e a temperatura com a viscosidade aparente dos fluidos de perfuração.

\subsection{Identificação da Rede Neuronal}

A arquitetura de rede neuronal utilizada neste trabalho foi o Perceptron Multi Camada ou Multilayer Perceptron (MLP). Este tipo de estrutura pertence à arquitetura feedforward de camadas múltiplas, cujo treinamento é efetivado de forma supervisionada. As redes MLP foram treinadas com algoritmo de backpropagation associado com o método de otimização de Levenberg-Marquardt e a topologia de rede foi especificada usando a técnica de validação cruzada.

O modelo neuronal adotado apresenta quatro entradas e uma saída e utilizou funções tangentes hiperbólicas na camada oculta, onde o número de neurônios ocultos variou de 4 a 14. Na camada de saída foi utilizado apenas um neurônio com função de ativação linear. As quatro entradas do modelo neuronal correspondem aos dados experimentais de composição de barita, bentonita e CMC, além da temperatura do fluido e a saída da rede são os respectivos valores de viscosidade aparente.

O procedimento de normalização é essencial quando se trabalha com redes neuronais artificiais. A experiência tem mostrado que o treinamento em RNA é geralmente mais eficiente quando os dados numéricos são escalados ou normalizados, de modo que suas magnitudes são semelhantes entre si. Os dados de entrada e saída foram normalizados na faixa de [-1 a 1] e depois misturados aleatoriamente e divididos em dois conjuntos para treinamento e validação, cada um contendo 288 e 97 pares de dados de entrada-saída, respectivamente. Cada modelo neuronal foi treinado pelo menos três vezes, usando diferentes conjuntos de pesos iniciais. A melhor rede foi determinada pelo menor erro quadrático médio do conjunto de dados de validação, de acordo com a Equação 1.

$$
E Q M=\frac{1}{n} \sqrt{\sum_{i=1}^{n}\left(\mu_{a p, \exp _{i}}-\mu_{a p, \text { pred }_{i}}\right)^{2}}
$$

sendo $\mu_{a p, \text { exp }}$ a viscosidade aparente experimental, $\mu_{a p, p r e d}$ a viscosidade aparente fornecida pela rede neuronal e $n$ o número de dados utilizados para treinamento ou validação.

\subsection{Algoritmo de Otimização}

Com o intuito de criar um aplicativo capaz de determinar a composição do fluido necessária para produzir a viscosidade aparente desejada, utilizou-se um Algoritmo Genético (AG) associado ao modelo neuronal do processo. O algoritmo AG/RNA foi projetado para ser capaz de determinar a composição do fluido de perfuração na etapa inicial de preparo, assim como durante o procedimento de correção de sua composição devido a eventuais perturbações que ocorrem durante a perfuração do poço, conforme descrito a seguir: 
Algoritmo de otimização no preparo do fluido: A viscosidade aparente desejada é alimentada no algoritmo de otimização, uma população inicial de soluções é gerada e usada como entrada do modelo neuronal do processo. A diferença entre a viscosidade desejada e a viscosidade estimada pela RNA é o parâmetro do processo evolutivo do AG. A evolução segue até que o critério de parada seja atingido e a solução obtida define as concentrações e a temperatura necessárias para atingir a viscosidade desejada.

Algoritmo de otimização na correção do fluido: No algoritmo para correção, as concentrações reais do fluido perturbado devem ser estabelecidas como entradas. Assim, o algoritmo de otimização calcula a viscosidade aparente da condição atual do fluido através do modelo neuronal e o algoritmo de evolução tem início até corrigir esse valor de viscosidade. Quando o processo de otimização chega ao fim, são obtidos os valores de correção que devem ser feitos nas concentrações dos componentes do fluido de perfuração para se atingir a viscosidade aparente desejada.

\section{RESULTADOS E DISCUSSÃO}

Como discutido anteriormente, redes neuronais com diferentes números de neurônios na camada interna foram avaliadas. A Figura 2 mostra a evolução do erro quadrático médio dos valores preditos para a viscosidade aparente durante as etapas de treinamento e validação em função do número de neurônios da camada oculta.

Figura 2 - Evolução do erro quadrático médio com o número de neurônios da camada oculta.

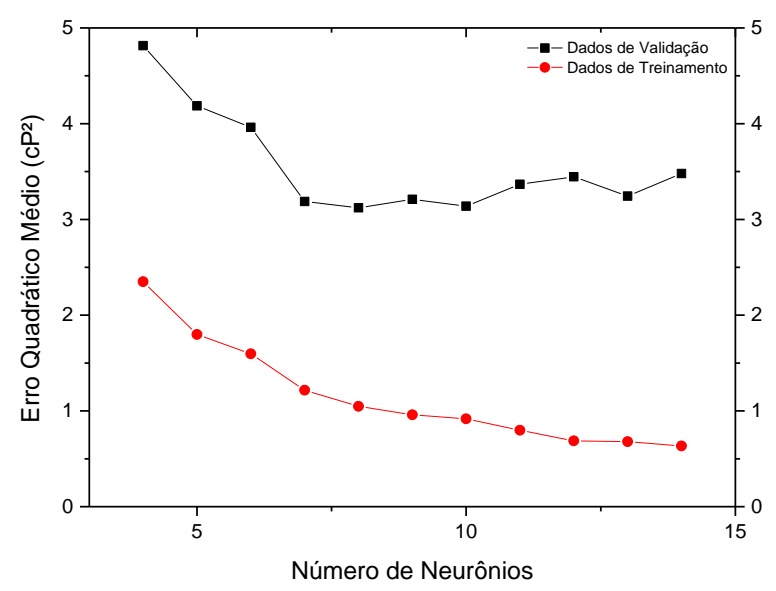

A partir dos resultados mostrados na Figura 2 é possível observar a diminuição assintótica do erro de predição associado aos dados de treinamento. Para este conjunto de dados o erro de predição diminui de modo inversamente proporcional ao aumento do número de neurônios na camada oculta. No entanto, observa-se um comportamento diferente para o conjunto de dados de validação, onde o valor do erro de predição passa por um mínimo. Esta característica do modelo neuronal é conhecida como overfitting e é caracterizada pela perda da capacidade de generalização devido à especialização nos dados de treinamento. Esse problema pode ser evitado selecionando-se a rede que apresentar o menor erro de predição para o conjunto de dados de validação. A rede neuronal escolhida como modelo do processo foi aquela com 8 neurônios na camada oculta, cujo erro quadrático médio previsto encontrado foi $3,12 \mathrm{cP}^{2}$. 
O Algoritmo AG/RNA foi projetado e modificado para os dois casos, utilizando novos conjuntos de experimentos para o preparo e correção do fluido (Tabelas 2 e 3, respectivamente). A viscosidade desejada foi testada no intervalo de 40 a $150 \mathrm{cP}$ para o algoritmo de preparo e de 50 a $150 \mathrm{cP}$ para o algoritmo de correção. A temperatura foi mantida fixa $\left(40^{\circ} \mathrm{C}\right)$ para cada experimento.

Tabela 2 - Erro percentual obtido no Algoritmo de Preparo.

\begin{tabular}{|c|c|c|c|c|c|}
\hline $\begin{array}{c}\mu_{\text {ap,exp }} \\
(\mathrm{cP})\end{array}$ & $\begin{array}{c}\mu_{\text {ap,pred }} \\
(\mathrm{cP})\end{array}$ & $\begin{array}{c}\text { Erro } \\
(\%)\end{array}$ & $\begin{array}{c}\mu_{\text {ap,exp }} \\
(\mathrm{cP})\end{array}$ & $\begin{array}{c}\mu_{\text {ap,pred }} \\
(\mathrm{cP})\end{array}$ & $\begin{array}{c}\text { Erro } \\
(\%)\end{array}$ \\
\hline \hline 40 & 41 & 2,5 & 100 & 76 & 24,0 \\
\hline 50 & 55 & 10,0 & 110 & 95 & 13,6 \\
\hline 60 & 63 & 5,0 & 120 & 98 & 18,3 \\
\hline 70 & 67 & 4,3 & 130 & 92 & 29,2 \\
\hline 80 & 63 & 21,3 & 140 & 114 & 18,6 \\
\hline 90 & 83 & 7,8 & 150 & 125 & 16,7 \\
\hline
\end{tabular}

Apesar de alguns resultados apresentarem erros percentuais acima de $20 \%$, o erro médio para o Algoritmo de Preparo foi de 14,3\% e para o Algoritmo de Correção, 7,25\%. Tais resultados demonstram o grande potencial da estratégia proposta neste trabalho.

\section{CONCLUSÃO}

Nesse trabalho foi desenvolvido um aplicativo para dar suporte ao preparo de fluidos de perfuração a base água. Desenvolveu-se uma ferramenta computacional capaz de estimar a viscosidade aparente de um fluido de perfuração em tempo real, além de determinar as correções necessárias na sua composição, caso seja necessário. Esta ferramenta, AG/RNA, é baseada em um Algoritmo Genético, associado a um modelo matemático do processo representado por uma rede neuronal artificial. O AG/RNA foi validado experimentalmente, apresentado erros médios de 14,3\% para o Algoritmo de Preparo e de 7,25\% para o Algoritmo de Correção, demonstrando grande potencial para resolver o problema apresentado.

\section{REFERÊNCIAS}

BOURGOYNE JR, A. T., Milheim, K., Chenevert, M., Young, F. Applied Drilling Engineering, SPE(2), 1991.

GUIMARÃES, I. B.; ROSSI, L. F. S. Estudo dos Constituintes dos Fluidos de Perfuração: Proposta de uma Formulação Otimizada e Ambientalmente Correta. $4^{\circ}$ PDPETRO Campinas, SP, outubro de 2007.

PETROBRAS. Ensaio de Viscosificante par Fluido de Perfuração Base de Água na Exploração e Produção de Petróleo. Método, N 2605, 1998.

TAVARES, R. M. Interpretação e análise de dados de perfuração em poços de petróleo. Dissertação (Mestrado). 145 p. Faculdade de Engenharia Mecânica e Instituto de Geociências, Universidade Estadual de Campinas, 2006.

THOMAS, J. E. (Organizador). Fundamentos da Engenharia de Petróleo. Rio de Janeiro: Editora Interciência, PETROBRAS, 2001. 